\title{
Fatores que influenciam os turistas para destinos ecogastronômicos
}

\author{
Factors that influence tourists for ecogastronomic destinations
}

\author{
Elisangela de Farias $^{1 \mathrm{i}}$ \\ Orcid: https://orcid.org/0000-0001-5265-1815
}

\author{
Adrielly Souza Silva ${ }^{2 i i}$ \\ Orcid: https://orcid.org/0000-0002-8259-8602
}

\author{
Marconi Freitas da Costa ${ }^{3 i i i}$ \\ Orcid: https://orcid.org/0000-0001-9888-8359
}

\begin{abstract}
Resumo
Este estudo objetivou mensurar de que maneira a intenção de visitar destinos ecogastronômicos poderia ser influenciada pelo consumo socialmente responsável, influência social e hábitos alimentares. Para tanto, sua natureza foi quantitativa e a estratégia de pesquisa utilizada foi o survey online. Os dados, por sua vez, foram tratados por meio da Modelagem de Equações Estruturais (MEE). Em linhas gerais, os resultados demonstram que a demanda constituinte desse potencial segmento turístico parece não ter como base os hábitos de consumo sócio e ambientalmente responsáveis, ao mesmo tempo em que não baseia as suas decisões nas opiniões e normativas sociais. Também foi percebido que os consumidores potenciais costumam ser indiferentes com o aspecto alimentício na formulação do seu interesse de visita. Logo, a principal contribuição da pesquisa está na sugestão do prazer e da experiência, elementos marcantes do turismo, como alguns dos fatores que podem sobrepor argumentos centrais da ecogastronomia uma vez que ela está associada aos destinos turísticos.

Palavras-chave: destino gastronômico; ecogastronomia; consumo socialmente responsável; influência social; hábitos alimentares do turista.
\end{abstract}

\begin{abstract}
This study aims to measure how the intention to visit eco-gastronomic destinations could be influenced by socially responsible consumption, social influence and eating habits. Therefore, it is of a quantitative nature and the online survey research strategy is used. The data, in turn, are analyzed using Structural Equation Modeling (SEM). In general, the results demonstrate that the constituent demand of this potential tourism segment does not seem to be based on socially and environmentally responsible consumption habits, at the same time that its decisions are not based on opinions and social norms. It is also noticed that potential consumers tend to be indifferent towards the food aspect in the formulation of their visiting interest. Therefore, the main contribution of this research is the suggestion of pleasure and experience, striking elements of tourism, as some of the factors that can override central arguments of ecogastronomy, since it is associated with tourist destinations.

Keywords: gastronomic destination; eco-gastronomy; socially responsible consumption; social influence; tourist eating habits.
\end{abstract}

\footnotetext{
${ }^{1}$ Universidade Federal de Pernambuco - UFPE, Brasil. E-mail: elisa jc2@hotmail.com

${ }^{2}$ Universidade Federal de Pernambuco - UFPE, Brasil. E-mail: dellysouzas@gmail.com

${ }^{3}$ Universidade Federal de Pernambuco - UFPE, Brasil. E-mail: marconi.fcosta@ufpe.br
} 


\section{INTRODUÇ̃̃̃O}

Os alimentos das localidades se constituem enquanto importantes atributos de desenvolvimento, haja vista que são singulares e auxiliam na sua promoção (ALDERIGHI; BIANCHI; LOZENZINI, 2016). Desse modo, a gastronomia local pode ser um fator de motivação para os visitantes (BERBEL-PINEDA et al., 2019). Em meio a esse cenário, surgem os destinos gastronômicos, utilizando-se da alimentação regional como fomento à prática turística nas destinações.

Nos últimos anos, contudo, o comportamento do consumidor tem passado por algumas transformações, sobretudo socioambientais, situação que não foi diferente em se tratando do consumo de alimentos. Nota-se a ascensão de preocupações com a saudabilidade da alimentação (BEVILACQUA; SILVA; SILVA, 2018) e, por conseguinte, a acentuação de sistema produtivo mais sustentáveis (CASTRO NETO et al., 2010; NASCIMENTO; COSTA; OLIVEIRA, 2015). Diante dessa nova perspectiva, em consonância às tendências globais do turismo, surgiu o fenômeno da ecogastronomia (SCHNEIDER, 2018).

$\mathrm{O}$ fenômeno a que se refere tem origem no movimento slow food, no qual representa a união da ética e o prazer da alimentação. Com isso, restitui ao alimento sua dignidade cultural, proteção de espécies vegetais e animais, da cozinha típica local, e propõe uma revisão na busca por prazer no alimento (SLOW FOOD, 2007). Isso diz respeito não apenas ao meio ambiente, mas também à cultura e à produção de alimentos no destino (SCHNEIDER, 2018). Esses locais dão preferência aos ingredientes nativos, ausente de agrotóxicos, além de priorizar os insumos provenientes da agricultora familiar. Dessa forma, os destinos ecogastronômicos estimam atrair visitantes interessados na sustentabilidade local (GIZELAK-KOTULSKA et al., 2011), atuando como um modelo alternativo ao turismo convencional (BLANCO, 2011).

Nesses destinos, a produção orgânica e o desenvolvimento sustentável das localidades representam valores significativos (CASTRO NETO et al., 2010). De tal modo, podem ser mais propensos a atrair consumidores cujo consumo é socialmente responsável (HASFORD; FARMER, 2016; PEREIRA et al., 2017). Isso porque, nesses casos, os indivíduos estão mais dispostos a efetuar decisões de compra ecologicamente conscientes, optando, em geral, por produtos com apelos socioambientais (LAU, 2010). A demanda, portanto, é constituída por sujeitos que se interessam na compra de atividades não degradantes (IRLENBUSCH; SAXLER, 2019), tal como se propõem os destinos ecogastronômicos.

Para mais, também se pressupõe que a intenção de visitar destinos ecogastronômicos seja afetada pela influência social. Isso porque, conforme Batista e Lima (2013), por exemplo, os indivíduos inseridos em ambientes com preocupações sociais e ambientais tendem a expressar esse comportamento na escolha e consumação dos seus alimentos. De tal modo, podem dar preferência à produção orgânica e sustentável, percebendo a gastronomia como elemento modificador de relações sociais e culturais (BERBELPINEDA et al., 2019), características que se assemelham aos ideais da ecogastronomia.

Por fim, considera-se que a demanda constituinte dos destinos em questão seja influenciada pelos hábitos alimentares dos viajantes. Alguns estudos, a exemplo de Pinheiro (2008), deram indícios de que este atributo pode ser determinante no comportamento dos consumidores. Ao considerar que, no caso dos destinos turísticos, as escolhas são formadas pelos mais diversos fatores, dentre os quais estão os sociais e psicológicos, a rotina de alimentação dos indivíduos pode se estender às escolhas e práticas turísticas 
(CARDOSO et al., 2015). De tal modo, a degustação da culinária local pode se constituir como um importante atrativo (YEONG; ANITA, 2012), especialmente nas destinações ecogastronômicas.

A contribuição mercadológica desta pesquisa decorre da investigação de um fenômeno com potencial de desenvolvimento sustentável para as localidades. Por se constituírem como contraponto aos modelos degradantes do turismo convencional, os destinos ecogastronômicos merecem maior atenção por parte dos estudiosos. Do ponto de vista acadêmico, este estudo demonstra originalidade ao investigar de forma conjunta três construtos que, embora já tenham sido investigados pelo campo acadêmico, ainda não foram pesquisados de forma integrada. Assim, este artigo teve como objetivo investigar de que maneira a intenção de visitar um destino ecogastronômico pode ser influenciada pelo consumo socialmente responsável (CSR), a influência social no consumo de alimentos (IS) e os hábitos alimentares dos turistas (HAT).

\section{REFERENCIAL TEÓRICO}

\subsection{Destino Gastronômico}

Do ponto de vista semântico, a gastronomia se refere à comida tradicional de uma determinada região, enquanto os destinos dizem respeito aos locais aos quais se pretende chegar. Logo, os destinos gastronômicos podem ser compreendidos como os lugares para os quais se deseja ir com o intuito de apreciar as comidas tradicionais. Nesses casos, os alimentos são responsáveis por impulsionar as destinações, fomentando, por exemplo, a produção local, os festivais culinários e os restaurantes (ELLIS; PARQUE; KIM; YEOMAN, 2018). Contudo, costuma ser concretizado nas situações em que as destinações contêm valores históricos e culturais a ele agregados (HILLEL; BELHASSEN; SHANI, 2013).
Nesse sentido, Alderighi, Bianchi e Lorenzini (2016) destacam que a agricultura e culinária local se constituem como importantes atributos para o desenvolvimento turístico de uma região, especialmente porque podem resultar em singularidade e sustentabilidade. De tal modo, um trabalho comunicacional eficaz no intuito de promover os recursos culturais dos destinos, dentre quais se encontra a gastronomia, pode ajudar a alavancar a atividade no local (COHEN; AVIELI, 2004). Entretanto, os gestores precisam lidar com algumas questões que podem ser intervenientes, a exemplo do paladar e dos costumes gastronômicos que são naturais dos visitantes e podem divergir da cultura local (SENGEL et al., 2015).

Além disso, destaca-se que a culinária exerce papel de destaque nas viagens. Por meio do estímulo aos sentidos, tais como a visão, olfato e paladar, ela corresponde a um terço dos gastos totais com a visitação turística (SENGEL et al., 2015). Isso se dá de tal modo que, segundo Alderighi, Bianchi e Lozenzini (2016), os produtos gastronômicos desempenham um papel significativo para o desenvolvimento econômico do destino. Embora a maioria das destinações ainda explore este segmento em plano secundário, é perceptível o seu potencial como motivador da atividade (LÓPEZ-GUZMÁN; CAÑIZARES, 2012).

Em alguns casos, cardápios culinários são consagrados como patrimônios culturais de determinadas localidades. De tal modo, a gastronomia se constitui como um símbolo de expressão cultural, evidenciando o organismo da comunidade local aos visitantes (PECCINI, 2013). Uma vez instituída como um recurso nativo de uma região, a culinária costuma ser apropriada pela atividade turística. Assim, segundo Long (2018), o turismo gastronômico concentra sua atenção na originalidade desse recurso, oferecendo aos turistas uma imersão na cultura local por meio dos sabores. 


\subsubsection{Ecogastronomia}

O conceito da ecogastronomia foi desenvolvido por Carlo Petrini e membros do movimento Slow Food, com a proposta de fomentar modelos alimentícios mais sustentáveis e saudáveis (RUBIM, 2013). O desenvolvimento desse movimento é um contraponto à cultura do Fast Food, haja os impactos negativos que este pode gerar sobre a comunidade em função da estreita ligação com o sistema de produção de alimentos locais (MIELI; MURDOCH, 2002). Ainda conforme os mesmos autores, parte-se do pressuposto de que os produtos típicos são características importantes de distinção cultural, portanto devem ser cultivados e protegidos.

Assim, os alimentos nativos são considerados endêmicos, haja vista que fazem parte da ecologia local e foram socialmente e historicamente produzidos, demarcando uma localidade (SCHNEIDER, 2018). Há, por conseguinte, um combate ao seu consumo destrutivo, estimando uma postura social e ambientalmente consciente (PIETRYKOWSKI, 2004). Propõe uma filosofia de vida que valoriza o ato da nutrição, ensina os prazeres dos sabores, reconhece as origens e os produtores responsáveis pelos alimentos e respeita os grupos sociais (REJOWSKI; RUBIM, 2013).

Neste cenário, o termo ecogastronomia surge como a união entre a ética e o prazer da alimentação. Seu intuito é congregar o respeito e o interesse na cultura gastronômica, de modo a apoiar o cultivo nativo dos alimentos, a biodiversidade agrícola e modelos de agricultura mais saudáveis e sustentáveis (SLOW FOOD BRASIL, 2010). De tal modo, preocupa-se com o meio ambiente e com o território de produção, além de estimar o não desperdício dos alimentos (SCHNEIDER, 2018). Além disso, segundo Tomazoni (2017), há uma preservação dos agricultores locais e escolha de ingredientes de qualidade.
As cidades que se envolvem no ideal da ecogastronomia, calcadas no movimento slow food, anseiam de forma primordial pela qualidade de vida dos moradores. De forma paralela, oferecem aos turistas ambientes apropriados e ecologicamente responsáveis, considerando não apenas a alimentação, mas também o ar, o solo, a água e fontes alternativas de energia (GIZELAK-KOTULSKA et al., 2011). Isso, por sua vez, é capaz de impulsionar de forma sustentável o turismo gastronômico, uma vez que cria experiências autenticas com a cultura local e ressalta a qualidade e sabor dos alimentos (MARTINS; GURGEL; MARTINS, 2016).

\subsection{Consumo Socialmente Responsável}

Nos últimos anos, tem crescido a preocupação dos indivíduos com a qualidade socioambiental do que consomem (CASTRO NETO et al., 2010). De tal modo, tem sido comum a atuação de consumidores engajados na busca por empresas com boa imagem mercadológica, ética profissional e responsabilidade ecológica (NASCIMENTO, 2019). Se constitui, dessa maneira, o consumo socialmente responsável. As organizações, contudo, se apropriam deste atributo comportamental no intuito de influenciar os consumidores à compra com argumentos de sustentabilidade (HASFORD; FARMER, 2016).

Em um contexto global, a sociedade tem percebido que o ato de consumo não deve estar associado com a devastação ambiental, tampouco com o desperdício de recursos naturais (LAU, 2010). Isso, porém, expressa a preocupação dos indivíduos com a sustentabilidade do planeta, fato que não está alheio às suas decisões de compra (CASTRO NETO et al., 2010). Entretanto, o consumo socialmente responsável está, também, aliado à sensibilidade com causas sociais. Isso porque, nesse eixo, ainda há alguns desafios a serem superados, a exemplo da desigualdade e redução da pobreza (PÉREZ-BAREA et al., 2017). 
Nesse cenário, nota-se que os consumidores têm ponderado acerca dos seus impactos sociais e ambientais no ato da compra, criando modelos mentais para a aquisição de produtos que dialogam com os seus ideais (PÉREZ-BAREA, et al., 2017). Muito embora algumas instituições atendam a essa demanda latente por acreditarem na importância das causas socioambientais, outras $\mathrm{o}$ fazem pela recompensa financeira (WEBB; MOHR; HARRIS, 2007). De toda forma, o bemestar humano começa a ser percebido pelas organizações como consequência do bemestar do planeta (CESAR; SANTOS; MOREIRA, 2018).

Não há como desconsiderar, portanto, que os destinos ecogastronômicos têm enquanto um dos seus pilares a preocupação com as causas sociais e ambientais das localidades turísticas (REJOWSKI; RUBIM, 2013). Desse modo, os visitantes buscam experiências que refletem conexões emocionais com os residentes, além de aproximação com a natureza e com o organismo local (SILKES; CAI; LEHTO, 2012; CESAR; SANTOS; MOREIRA, 2018). Motivos como esses levam a crer que a demanda constituinte desse segmento é composta pelos indivíduos que apresentam maior propensão ao consumo socialmente responsável. Diante do exposto, desenvolve-se a primeira hipótese desse estudo, a saber:

H1: O consumo socialmente responsável influencia positivamente a intenção de visitar um destino turístico ecogastronômico.

\subsection{Influências Sociais no Consumo de Alimentos}

Conforme estudos da psicologia social, nenhum indivíduo se tornará adulto sem agir sobre a influência de outrem (RODRIGUES, 2018). Acerca disso, Kelman (2006) argumenta que a conformidade social na influência e na aceitação dos sujeitos ocorre por intermédio de outras opiniões e posicionamentos. Contudo, se estende aos mais diversos comportamentos, inclusive os alimentares. Argumenta-se, por exemplo, que as crianças iniciam uma associação alimentar por meio da família, responsável por prédeterminar os seus hábitos gastronômicos (PEREIRA, 2013).

Ainda conforme Kelman (2006), há três processos por meio dos quais os indivíduos são influenciados por outros, quais sejam: (1) Conformidade, que ocorre quando um indivíduo recebe a influência de um outro no intuito de alcançar uma reação favorável dele, ganhar aprovação ou evitar desaprovação b) Identificação, situação em que o indivíduo recebe influência a fim de estabelecer ou manter uma relação satisfatória; c) Internalização, ocorre quando o indivíduo aceita a influência do outro, de modo a manter a congruência de ações e crenças com o seu próprio sistema de valores.

No consumo de alimentos, em particular, há a influência de diversos aspectos psicológicos desenvolvidos por contextos sociais. Como exemplo, pode-se mencionar as crenças dos sujeitos sobre uma alimentação saudável, a atitude frente à dieta, além da responsabilidade sobre o consumo e preparo das refeições (TORAL; SLATER, 2007). O consumo de alimentos, portanto, desempenha um papel fundamental nas interações humanas. Além de se constituir como um direito cívico, é considerado uma atividade cultural que se inicia desde os primeiros anos de vida (BATISTA; LIMA, 2013; PEREIRA, 2013).

Do ponto de vista do turismo, em particular, especialmente dos destinos turísticos, a busca por novas experiências conduz os visitantes a lugares nos quais exista a possibilidade de desfrutar da cultura local, em muito expressa pela culinária nativa (LÓPEZ-GUZMÁN; CAÑIZARES, 2012). A gastronomia se consolida, portanto, como um importante atrativo, de tal modo que os sabores e as suas origens podem ser determinantes na escolha pelas 
destinações (SENGEL et al., 2015; ALDERIGHI; BIANCHI; LOZENZINI, 2016). Contudo, diante do que foi exposto acerca do comportamento alimentício, não é possível desconsiderar que a intenção de visita seja impactada pelas influências sociais. Dito isso, propõe-se a segunda hipótese desta pesquisa:

H2: A influência social no consumo de alimentos influencia positivamente a intenção de visitar um destino ecogastronômico.

\subsection{Hábitos Alimentares dos Turistas}

Os hábitos alimentares correspondem às atitudes dos indivíduos face aos alimentos, caracterizando-se pela repetição destas. É o meio por meio do qual os sujeitos respondem às pressões sociais e se expressam culturalmente (PINHEIRO, 2008; VAZ; BENNEMANN, 2014). Segundo Pinheiro (2008), o consumo alimentar depende de diversos fatores, tais como os socioculturais e religiosos, as influências publicitárias, o status e o prestígio atribuído ao alimento. Esses elementos, por sua vez, são determinantes para a formação das escolhas alimentares, refletindo crenças, padrões e diferenças sociais (FREEDMAN, 2015).

No que concerne à atividade turística, especificamente, a consumação dos hábitos alimentares nas destinações não apenas satisfaz as necessidades fisiológicas dos viajantes, mas também fomenta experiências culturais, por meio das quais se pode interagir com os anfitriões (CETIN; DINCER; ERTUGRAL, 2015). De tal modo, é possível valorizar a identidade do destino, tendo em vista que a culinária tradicional agrega valor à localidade (SENGEL et al., 2015; GIMENESMINASSE, 2015). Assim, conforme Yeong e Anita (2012), a degustação da culinária local se torna parte fundamental dos atrativos turísticos.

Entretanto, segundo Mak, Lumbers, Eves e Chang (2012) e, mais recentemente,
Cetin, Dincer e Ertugral (2015), a culinária costuma ser negligenciada pelos destinos, haja vista que é percebida apenas como recurso de apoio e não como um atrativo. Há alguns anos, contudo, Kivela e Crotta, (2006) e Gândara, Gimenes, Mascarenhas, (2009) chamavam a atenção para a importância do consumo de alimentos nas destinações. Um dos motivos pelos quais isso ocorre é que os hábitos alimentares, especialmente os serviços a eles associados, podem acentuar a competitividade dos destinos, uma vez que atraem o interesse de visita dos turistas (GIMENES-MINASSE, 2015).

No caso específico dos destinos ecogastronômicos, há um estímulo à visitação através de argumentos de sustentabilidade e do fomento à culinária ecologicamente responsável. Desse modo, estima-se uma experiência gastronômica memorável (CETIN; DINCER; ERTUGRAL, 2015). Entretanto, isso pode não estar isento à influência dos hábitos alimentares dos turistas, tendo em vista que isso reflete o seu envolvimento com a identidade local. Diante do exposto, sugere-se a terceira hipótese desta pesquisa:

H3: Os hábitos alimentares do turista influenciam positivamente a intenção de visitar um destino ecogastronômico.

Contudo, o hábito alimentar de um indivíduo possui características de acordo com as repetições das suas escolhas alimentares (VAZ; BENNEMANN, 2014). Entretanto, ainda segundo os autores, essas escolhas podem ser influenciadas por fatores que englobem alimentos saudáveis. De igual modo, Rubim (2013) desperta para necessidade de o indivíduo estar bem informado quanto aos alimentos, valorizando o ciclo de produção e obtendo responsabilidade de resguardar sua herança culinária, tradições e cultura.

Dito isso, os consumidores estão cada vez mais próximos do social, ético e ambiental, diante de um contexto de responsabilidade socioambiental (PÉREZ- 
BAREA et. al., 2017). Para Gândara e Gimenes (2009), o alimento evidencia um resgate das emoções, memórias e identidade de uma localidade, demonstrando a importância da memória culinária de uma sociedade e contribuindo, assim, para a inclusão social. Logo, formula-se a seguinte hipótese:

H4: O consumo socialmente responsável influencia positivamente os hábitos alimentares.

Para mais, Batista e Lima (2013) e, mais recentemente, Vaz e Bennemann (2018) afirmam que a consumação de alimentos é, ainda, um ato social. Desse modo, vai muito além do suprimento das necessidades básicas de um indivíduo. A alimentação é frequentemente direcionada a um papel de interações sociais, tanto no âmbito familiar quanto comunitário (BATISTA; LIMA, 2013; VAZ;
BENNEMANN, 2018). Tais interações podem, portanto, conduzir o indivíduo a determinadas escolhas alimentares de acordo com os grupos aos quais pertencem, respondendo, em alguns casos, a pressões sociais e culturais (VAZ; BENNEMANN, 2018).

Também é possível enfatizar que a avaliação e opinião de outros indivíduos (familiares e amigos, por exemplo) tem impacto no consumo de alimentos (TORAL; SLATER, 2007). Esse comportamento possui associações com práticas alimentares, transformando, desse modo, as ações que se associam ao ato de consumo alimentício (VAZ; BENNEMANN, 2018). Diante desse pressuposto teórico, pode-se destacar a quinta e última hipótese formulada por esse estudo:

H5: As influências sociais estão associadas positivamente com os hábitos alimentares.

\subsection{Proposição do modelo teórico}

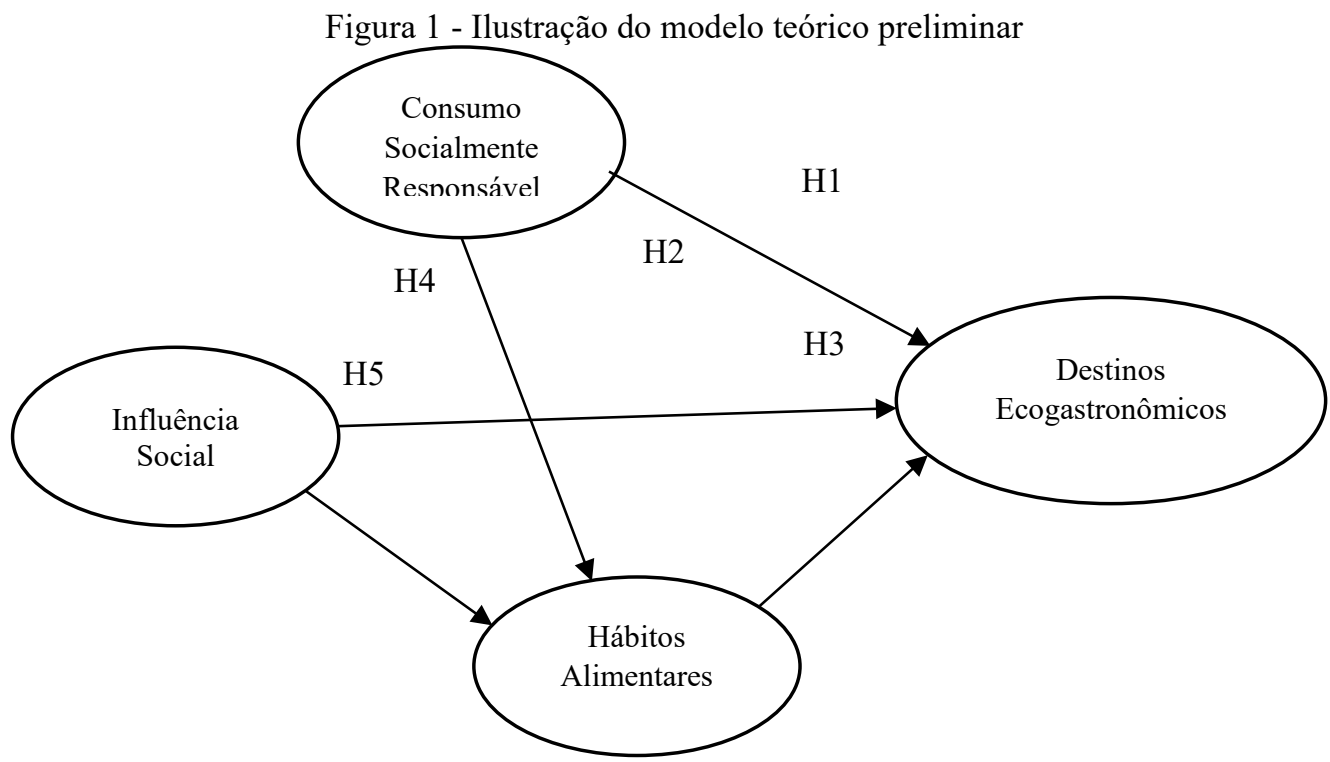

Fonte: Elaborada pelos autores. 


\section{MÉTODO DA PESQUISA}

Este estudo teve como propósito investigar a influência dos construtos Consumo Socialmente Responsável (CSR), Influências Sociais (IS) e Hábitos Alimentares do Turista (HAT) sobre a intenção de visita a um destino ecogastronômico. Esta pesquisa foi pautada em um posicionamento pragmático positivista (SACCOL, 2019), com abordagem quantitativa. Para tal estudo, assim como deve ser feito em outros de semelhante abordagem, é importante que haja planejamento dos procedimentos, detalhada descrição e, ainda, que estes sejam seguidos com rigor ao longo da investigação (CRESWELL, 2010).

Os procedimentos adotados foram a pesquisa bibliográfica e a pesquisa de campo. A condução de um estudo bibliográfico foi relevante para que houvesse melhor entendimento dos temas apresentados. A busca por materiais que abordam o assunto foi realizada nas principais plataformas de pesquisa, nomeadamente Periódicos Capes, Science Direct, SPELL, e Google Acadêmico. A busca foi dirigida a artigos científicos relacionados aos construtos dessa pesquisa, com o intuito de esclarecer e embasar os conceitos por ela apresentado.

\subsection{População e amostra}

Utilizou-se como método de coleta de dados a pesquisa survey on-line, a qual caracteriza-se pela forma objetiva de interrogar os indivíduos, a fim de receber de um grupo considerável de pessoas informações relacionadas ao problema investigado, por meio da análise quantitativa, de forma a obter resultados correspondentes às informações coletadas (GIL, 2008). Tendo em vista a impraticidade em definir a totalidade dos integrantes desse universo a amostra do estudo foi do tipo não probabilística
(MALHOTRA, 2012), utilizando técnicas de amostragem por conveniência e bola de neve. Com relação às características amostrais e temporais utilizou-se o corte transversal único, indicando que o procedimento de coleta foi realizado uma única vez.

O questionário utilizado como instrumento de coleta foi composto por 24 itens numa escala do tipo Likert de 7 pontos, na qual 1 corresponde a discordo totalmente e 7 corresponde ao maior grau de concordância. A fim de traçar um perfil dos respondentes, o instrumento contou ainda com sete questões relacionadas à idade, sexo e frequência de viagens. A distribuição da pesquisa foi feita por meio de um link on-line, disponibilizado nas redes sociais e encaminhado por e-mail. $\mathrm{O}$ questionário foi instrumentalizado através dos formulários on-line do Google Forms.

As questões que levaram ao instrumento de pesquisa foram extraídas de escalas desenvolvidas e validadas por outros autores. Após a revisão da literatura, optou-se, primeiramente, pela escala Consumo Socialmente Responsável desenvolvida por Webb, Mohr e Harris (2007). Nesta, especificamente, apenas duas das quatro dimensões criadas foram utilizadas. Isso porque, por tratarem mais diretamente dos critérios de compra dos consumidores, estas demonstraram ser mais adequadas ao que este estudo propõe.

$\mathrm{O}$ construto Influência Social, por sua vez, foi mensurado a partir da escala desenvolvida por Lenox e Wolfe (1984), com a qual optou-se pela utilização de apenas uma das quatro dimensões. Por fim, mensurou-se o construto Hábitos Alimentares do Turista por meio da escala de Kim e Evis (2012). Esta, em particular, trata de sete dimensões que compõem motivos de viagens direcionada à gastronomia, sendo, portanto, utilizadas todas as dimensões propostas pela escala. No quadro abaixo, é possível notar mais detalhadamente essas informações. 
Quadro 1 - Composição do instrumento de coleta

\begin{tabular}{|c|c|c|c|}
\hline Construto & $\begin{array}{l}\text { Autoria da } \\
\text { escala }\end{array}$ & Itens (dimensões e variáveis) & Código \\
\hline $\begin{array}{l}\text { Consumo } \\
\text { socialmente } \\
\text { responsável }\end{array}$ & $\begin{array}{l}\text { Webb, Mohr e } \\
\text { Harris (2007) }\end{array}$ & $\begin{array}{l}\text { Dimensão: Critérios de impactos ambiental da compra e } \\
\underline{\text { uso }} \\
\text { - Evito comprar de empresas que prejudicam plantas ou } \\
\text { animais ameaçados. } \\
\text { - Sempre que possível, ando a pé, ando de bicicleta, viajo } \\
\text { de carro ou uso de transporte público para ajudar a } \\
\text { reduzir a poluição do ar } \\
\text { - Evito usar produtos que poluem o ar } \\
\text { - Evito comprar produtos que poluem a água } \\
\text { - Eu faço um esforço para evitar produtos ou serviços } \\
\text { que causam danos ambientais } \\
\text { - Limito meu uso de energia, como eletricidade ou gás } \\
\text { natural, para reduzir meu impacto no meio ambiente }\end{array}$ & $\begin{array}{l}\text { CSR01 } \\
\text { CSR02 } \\
\text { CSR03 } \\
\text { CRS04 } \\
\text { CSR05 } \\
\text { CRS06 }\end{array}$ \\
\hline Influência Social & $\begin{array}{l}\text { Lenox e Wolfe } \\
\text { (1984) }\end{array}$ & $\begin{array}{l}\text { Dimensão: Capacidade de modificar autoapresentação } \\
\text { - Eu tenho a habilidade de controlar o modo como me } \\
\text { deparo com as pessoas, dependendo da impressão que } \\
\text { desejo dar a elas. } \\
\text { - Quando sinto que a imagem que estou retratando não } \\
\text { está funcionando, posso prontamente mudá-la para algo } \\
\text { que transmita a imagem que preciso. }\end{array}$ & IS01 \\
\hline $\begin{array}{l}\text { Hábitos } \\
\text { Alimentares de } \\
\text { Experiência } \\
\text { Cultural }\end{array}$ & $\begin{array}{l}\text { Kim e Evis } \\
(2012)\end{array}$ & $\begin{array}{l}\text { Dimensão: Experiência cultural } \\
\text { - Experimentar a comida local me dá a oportunidade de } \\
\text { aumentar meu conhecimento sobre diferentes culturas. } \\
\text { - Experimentar a comida local me ajuda a ver como as } \\
\text { outras pessoas vivem. } \\
\text { - Experimentar comida local me permite descobrir algo } \\
\text { novo. } \\
\text { - Degustar comida local em um lugar original é uma } \\
\text { experiência autêntica. } \\
\text { - É importante para mim provar a comida local em suas } \\
\text { regiões originais (países). }\end{array}$ & $\begin{array}{l}\text { HAB01 } \\
\text { HAB02 } \\
\text { HAB03 } \\
\text { HAB04 } \\
\text { HAB05 }\end{array}$ \\
\hline $\begin{array}{l}\text { Intenção de visitar } \\
\text { destinos } \\
\text { ecogastronômicos }\end{array}$ & $\begin{array}{l}\text { Elaborado pelos } \\
\text { autores (2018). }\end{array}$ & $\begin{array}{l}\text { Ecogastronomia trata da gastronomia evidenciando a } \\
\text { cultura de uma localidade, preocupando-se com a } \\
\text { sustentabilidade e a degradação do meio ambiente. Leva } \\
\text { aos mais diversos bares e restaurantes produtos que têm } \\
\text { origem direta do produtor rural, favorecendo a produção } \\
\text { agrícola local. } \\
\text { Eu tenho intenção de visitar (conhecer) um destino } \\
\text { turístico ecogastronômico. }\end{array}$ & IVDE1 \\
\hline
\end{tabular}

Fonte: Elaborado pelos autores.

Após a sua elaboração o questionário foi submetido ao processo de validação de conteúdo por meio da análise de pesquisadores da área do turismo. Recebidas as recomendações desses avaliadores, alguns itens foram alterados e o instrumento ora refinado foi sujeitado a um pré-teste com 15 respondentes, com características semelhantes à população estudada e que serão contabilizados na amostra final desta pesquisa. O pré-teste ocorreu entre os dias 29/01/2019 a $01 / 02 / 2019$, seguido pelo período de coleta de dados entre 03/02/2019 a 26/02/2019.

\subsection{Procedimentos de análise dos dados}

A princípio, a análise dos dados ocorreu por meio da estatística descritiva, com frequência, média e desvio padrão. 
Objetivou-se, nesse momento, verificar e delimitar o perfil sociodemográfico da amostra. $\mathrm{Na}$ sequência, realizaram-se estatísticas inferenciais por meio da técnica de Modelagem de Equações Estruturais (MEE). Para tanto, o Statistical Package for the Social Sciences (SPSS) foi utilizado. Esse método foi considerado o mais adequado tendo em vista que os seus coeficientes constatam possíveis relações entre variáveis latentes, tal como neste estudo.

\section{RESULTADOS}

Todos os questionários respondidos, após revisados, foram contemplados na amostra final $(n=118)$. Assim, momento seguinte foi destinado à importação da base dos dados no SPSS, prosseguido pelas análises realizadas com o auxílio do software.

\subsection{Perfil sociodemográfico}

O primeiro passo voltou-se à definição do perfil sociodemográfico da amostra coletada por meio de estatística descritiva de frequência e percentual. As informações relacionadas aos dados demográficos dos respondentes, coletadas por meio das perguntas específicas de tal assunto contidas no questionário, foram resumidas no Quadro 2. Os indivíduos que compõem a amostra desta pesquisa são, em maioria, do gênero masculino, correspondendo a $67,6 \%$ do total. O nível de escolaridade completo predominante foi o ensino superior $(50,8 \%)$. Por fim, a frequência anual em que os indivíduos realizam viagens também foi averiguada. Conforme Quadro 2, a maioria, representada por $36,4 \%$ do total, afirma viajar no máximo 2 vezes por ano.

Quadro 2 - Perfil sociodemográfico dos respondentes

\begin{tabular}{|l|l|}
\hline \multicolumn{2}{|c|}{ Frequência anual de viagens } \\
\hline Sem resposta & $5,1 \%$ \\
\hline Máximo 1 vez por ano & $33,2 \%$ \\
\hline 2 vezes ao ano & $36,4 \%$ \\
\hline 3 vezes ao ano & $17 \%$ \\
\hline 6 vezes ao ano & $2,5 \%$ \\
\hline 10 vezes no ano & $0,8 \%$ \\
\hline 24 vezes ao ano & $0,8 \%$ \\
\hline Nunca Gênero & $2,5 \%$ \\
\hline Outros & $1,7 \%$ \\
\hline \multicolumn{2}{|c|}{ Nível de escolaridade completo } \\
\hline Feminino & $42,4 \%$ \\
\hline Masculino & $0,8 \%$ \\
\hline \multicolumn{2}{|c|}{ com } \\
\hline Ensino fundamental & $17 \%$ \\
\hline Ensino médio & $50,8 \%$ \\
\hline Ensino superior & $31,4 \%$ \\
\hline Pós-graduação & $2019)$ \\
\hline
\end{tabular}

Fonte: Pesquisa de campo (2019).

Ainda no tocante ao perfil sociodemográfico dos respondentes, algumas variáveis foram extraídas em escala razão, estimando maior precisão numérica a partir de médias e desvio padrão. As informações estão dispostas no Quadro 3. Em geral, tem-se que a idade média dos sujeitos é de 36,4 anos, já a renda média mensal familiar é de $\mathrm{R} \$ 5.818,04$. Sendo o número médio de pessoas que dividem a residência 3,55 , a renda per capita da amostra é de R\$1.638,88, valor que foi mensurado com base no quociente da renda familiar mensal e a quantidade de pessoas que vivem na residência. 
Quadro 3 - Perfil sociodemográfico dos respondentes e desvio padrão

\begin{tabular}{|l|l|l|}
\hline Variáveis & Média & Desvio padrão \\
\hline Idade & 36,40 & 10,197 \\
\hline Renda média mensal (familiar) & $\mathrm{R} \$ 5.818,04$ & $\mathrm{R} \$ 4.824,525$ \\
\hline Quantidade de pessoas na residência & 3,55 & 1,234 \\
\hline
\end{tabular}

Fonte: Pesquisa de campo (2019).

Na sequência, o esforço foi direcionado para a análise da consistência das escalas do questionário, seguido da dimensionalidade dos dados. Assim, a próxima seção abordará esses resultados, necessários para a realização da análise de regressão múltipla.

\subsection{Modelo de mensuração}

Seguindo os protocolos de Marôco (2010), verificou-se a possível existência e posterior remoção de outliers da amostra. Para tanto, utilizou-se a Distância Quadrada de Mahalanobis $\left(\mathrm{D}^{2}\right)$. Nessa etapa, não foram observados índices discrepantes que indicassem necessidade de extração da amostra. Posteriormente, realizou-se a análise fatorial, momento no qual os itens CSR03 e CSR05, ambos referentes ao Consumo Socialmente Responsável, foram retirados.

Uma vez refinados os itens cerne dos construtos, realizou-se uma nova análise. Nesse momento, os índices resultantes do modelo de mensuração indicaram uma boa adequação de ajustamento do modelo. Para fins de verificação, apresentam-se os índices, a saber: X2/df $(68,973 / 51)=1,352(\mathrm{p}=$ $0,048) ; \mathrm{GFI}=0,914 ;$ IFI $=0,983$; TLI $=$ 0,977; $\mathrm{CFI}=0,982 ; \mathrm{NFI}=0,936$; $\mathrm{PCFI}=$ 0,759 ; RMSEA $=0,055$; $\mathrm{PCLOSE}=0,383$; $\mathrm{ECVI}=1,051 ; \mathrm{MECVI}=1,109$.

Ainda no modelo de mensuração, objetivando investigar o nível de adequação das escalas, foram averiguadas as análises de confiabilidade, a partir do alfa de Cronbach, e a composta (CC). Em ambos, o valor de referência é $\geq 0,7$ (HAIR et al., 2010). Conforme nota-se na Tabela 2 , todos os índices resultantes atingiram o que se esperava, indicando que há consistência interna dos itens em cada escala.

Tabela 2 - Estatística descritiva, confiabilidade e validade

\begin{tabular}{lccccc}
\multicolumn{1}{c}{ Variáveis } & Média & D.P. & Cronbach & CC & AVE \\
Consumo Socialmente Responsável (CSR) & 4,970 & 1,497 & 0,806 & 0,724 & 0,515 \\
Influência Social (IS) & 4,840 & 1,530 & 0,756 & 0,745 & 0,649 \\
Hábitos Alimentares (HAB) & 5,420 & 1,630 & 0,963 & 0,960 & 0,832 \\
Intenção de Visitar Destinos Ecogastronômicos (IVDE) & 6,270 & 1,189 & -- & -- & -- \\
\hline Nota. DP (Desvio-padrão); CC (Confiabilidade Composta); AVE (Variância Extraída Média) &
\end{tabular}

Posteriormente, verificaram-se as validades fatoriais, convergente $\mathrm{e}$ discriminante das escalas. Na primeira, os coeficientes padronizados, relativos a cada item, foram averiguados. Como todos resultaram em $\geq 0,5$, houve comprovação da validade fatorial. Já, a validade convergente foi testada com base nos índices da variância média explicada (AVE). Nesse caso, a boa adequação dos valores também foi mensurada considerando $\geq 0,5$. $\mathrm{Na}$ Tabela 3, verifica-se que todos os construtos alcançaram a referência estatisticamente aceitável.

Tabela 3 - Correlações, Variância compartilhada e AVE

\begin{tabular}{lccc}
\multicolumn{1}{r}{ Variáveis } & CSR & IS & HAB \\
\hline CSR & $\mathbf{0 , 5 1 5}$ & 0,165 & 0,102 \\
IS & 0,407 & $\mathbf{0 , 6 4 9}$ & 0,099 \\
HAB & 0,318 & 0,314 & $\mathbf{0 , 8 3 2}$ \\
\hline
\end{tabular}

Nota. Os valores das AVE estão na diagonal da tabela (em negrito), os valores abaixo da diagonal são as correlações e os acima são as variâncias compartilhadas (correlações ao quadrado). 
Por fim, a validade discriminante foi testada. Para tanto, verificou-se se a AVE de cada um dos construtos resultou em um valor acima das variâncias compartilhadas. Isso porque, como os construtos são teoricamente diferentes, não deve haver elevada correlação estatística entre eles. Tal como foi possível observar por meio da Tabela 3, essa condição foi atendida, indicando que também houve validade discriminante.

\subsection{Modelo estrutural}

Em concordância com os protocolos da MEE, prosseguiu-se para a análise do modelo estrutural. Nessa etapa, verificaram-se as relações entre as variáveis latentes do modelo de mensuração. Conforme nota-se na Tabela 4, foram obtidos novos índices de ajustamento. Com base nos resultados encontrados é possível afirmar que houve um bom ajustamento do modelo estrutural.

Tabela 4 - Índices de ajustamento do modelo

\begin{tabular}{l|c|l}
\hline \multicolumn{1}{c|}{ Índices } & Resultados & \multicolumn{1}{c}{ Critérios } \\
\hline $\mathrm{X}^{2} / \mathrm{Gl}(72,328 / 49)$ & 1,476 & {$[1 ; 2]$ Ajuste bom } \\
p-value & 0,017 & $>0,05$ Ajuste aceitável* \\
GFI & 0,912 & $>0,90$ Ajuste bom \\
IFI & 0,977 & $>0,95$ Ajuste muito bom \\
TLI & 0,969 & $>0,95$ Ajuste muito bom \\
CFI & 0,977 & $>0,95$ Ajuste muito bom \\
NFI & 0,933 & $>0,90$ Ajuste bom \\
PCFI & 0,725 & {$[0,70 ; 0,80]$ Ajuste aceitável } \\
RMSEA & 0,064 & $<0,08$ Ajuste bom \\
PCLOSE & 0,226 & $>0,05$ Ajuste muito bom \\
EVCI & 1,114 & Quanto menor é melhor \\
MEVCI & 1,176 & Quanto menor é melhor \\
\hline
\end{tabular}

*Amostras grandes apresentam mais sensibilidade para ter significância no $p$-value.

Sequencialmente, os coeficientes das relações entre as variáveis latentes foram verificados (conforme Tabela 5). Desse modo, foi possível testar as hipóteses pressupostas. Considerando $p$-value $\leq 0,05$ como o parâmetro estatístico, as hipóteses $\mathrm{H} 1(+), \quad \mathrm{H} 2(+)$ e $\mathrm{H} 3(+)$ não foram suportadas, uma vez que em todos esses casos o índice atingido foi superior ao esperado. Ênfase deve ser atribuída a $\mathrm{H} 2(+)$, visto que a relação pressuposta por ela resultou no valor mais elevado, indicando a maior rejeição.
As hipóteses $\mathrm{H} 4(+)$ e $\mathrm{H} 5(+)$, entretanto, foram confirmadas pela MEE. Nesses casos, o $p$-value resultante foi $\leq 0,05$, demonstrando que as relações pressupostas poderiam ser estatisticamente suportadas. Uma vez que a valência foi positiva, ambas puderam ser confirmadas. Salienta-se que a $\mathrm{H} 1(+)$ poderia ser marginalmente aceita considerando $p$-value $\leq 0,10$. Todavia, esse parâmetro não foi aderido tendo em vista um maior rigor estatístico.

Tabela 5 - Testes das hipóteses da pesquisa

\begin{tabular}{l|cccccc}
\multicolumn{1}{c|}{ Hipóteses } & $\begin{array}{c}\text { Coeficiente } \\
\text { padronizado }\end{array}$ & $\begin{array}{c}\text { Coeficiente } \\
\text { não } \\
\text { padronizado }\end{array}$ & S. $\boldsymbol{~ . ~}$ & $\boldsymbol{R} . \boldsymbol{C .}$ & $\boldsymbol{p}$ & Status \\
\hline H1(+): CSR $\rightarrow$ IVDE & 0,182 & 0,156 & 0,089 & 1,751 & 0,080 & Não suportada \\
\hline H2(+): IS $\rightarrow$ IVDE & $-0,097$ & $-0,067$ & $-0,084$ & $-0,796$ & 0,426 & Não suportada \\
\hline H3(+): HAB $\rightarrow$ IVDE & 0,161 & 0,140 & 0,088 & 1,584 & 0,113 & Não suportada \\
\hline H4(+): CSR $\rightarrow$ HAB & 0,251 & 0,247 & 0,098 & 2,508 & 0,012 & Suportada \\
\hline
\end{tabular}




\begin{tabular}{c|cccccc}
\hline H5(+): IS $\rightarrow$ HAB & 0,311 & 0,277 & 0,111 & 2,483 & 0,013 & Suportada \\
\hline \multicolumn{2}{r}{ Nota. $\mathrm{p} \leq 0,05 ; \mathrm{SE}=$ Erro padrão; $\mathrm{RC}=$ Rácio Crítico. }
\end{tabular}

\subsection{Análise das hipóteses}

Conforme resultados apontados pela rejeição da $\mathrm{H1}(+)$, o consumo socialmente responsável não é suficiente para explicar a intenção de visita em destinos ecogastronômicos. Nota-se uma coerência com o estudo de Sinderlar et al. (2018), uma vez que, segundo os autores, a maior consumação de produtos alimentícios sustentáveis provém do público feminino, sexo que foi menor representado por esta amostra. É importante ressaltar que este achado surpreende a medida em que o interesse por produtos socioambientais supostamente dialogaria com a característica sustentável dos destinos ecogastronômicos.

De tal modo, é possível compreender que, embora esses destinos se posicionem como ecologicamente responsáveis, os consumidores potenciais não são motivados por esta condição. Demonstra, assim, que esse argumento não consolida uma vantagem competitiva para as localidades. De acordo com Belem et al. (2017), os indivíduos maiores de 50 anos são os mais suscetíveis a tomarem decisões baseadas na preocupação com questões socioambientais. Como a amostra deste estudo foi composta, em sua maioria, por sujeitos mais jovens (36,4 anos, em média), é possível que as decisões de consumo destes correspondam mais fortemente a uma rotina menos socialmente responsável e mais prática.

A $\mathrm{H} 2(+)$, por sua vez, também apontou rejeição, tendo sido esta a que obteve o índice mais elevado de negação do pressuposto teórico. De tal modo, o estudo demonstra que as influências sociais não explicam o interesse de vista dos destinos aqui apontados. Apesar dos indivíduos serem considerados incapazes de agir sem a influência de outros (RODRIGUES, 2018), sendo estes afetados pelo grupo ao qual pertencem (KELMAN, 2006), para a decisão de visita a destinos ecogastronômicos isso não aplica. Uma possível explicação para esse resultado está na influência dos valores individuais dos sujeitos.

Muito embora o contexto social, sobre o qual há a intervenção cultural, possa definir decisões de consumo atreladas aos produtos alimentícios (VAZ; BENNEMANN, 2014), nos destinos ecogastronômicos isso pode estar mais relacionado com as crenças e valores particulares. Tal como apontam Batista e Lima (2013), na presença de pessoas desconhecidas, a exemplo do que acontece durante a realização das viagens, as decisões alimentícias não costumam ser motivadas pela opinião dos sujeitos mais próximos. De tal modo, o interesse de visitar destinos com posicionamento gastronômico não seria afetado pelas avaliações alimentares de conhecidos, como familiares e amigos.

Já, a H3 (+), que sugeria a antecedência dos hábitos alimentares dos turistas sobre a intenção de vista, também foi rejeitada. É possível que esse resultado seja um reflexo da ausência de colocação da gastronomia como argumento central de diferenciação nos destinos ecogastronômicos. Conforme Cetin, Dincer e Ertugral (2015), a culinária tende a ser negligenciada por essas destinações, tendo sendo posicionada apenas como um recurso de apoio turístico e não como um atrativo consolidado. Essa escassez de posicionamento pode ser a razão pela qual os consumidores potenciais parecem não ser motivados pelos interesses alimentícios.

Além disso, Mak, Lumbers, Eves e Chang (2012), reafirmados por Sengel et al. (2015), chamam a atenção para alguns elementos que podem influenciar negativamente o consumo de produtos gastronômicos, como os destinos investigados nesse estudo. De acordo com os autores, a neofilia, por exemplo, atributo 
que se refere à aversão ao novo, pode explicar a recusa por alimentos desconhecidos, como aqueles que são encontrados nas destinações turísticas. Nesse caso, há uma resistência a variedades de produtos ofertados pela gastronomia local. De tal modo, o quesito alimentício não seria suficiente para motivar os consumidores à visitação em destinos ecogastronômicos.

Adicionalmente, destaca-se que a $\mathrm{H} 4(+)$, por sua vez, foi confirmada, apontando que o consumo de produtos socialmente responsáveis tem influência sobre a formulação dos hábitos alimentares dos indivíduos. Isso está em consonância com o estudo de Vaz e Bennemann (2014), uma vez que, segundo os autores, os comportamentos mais saudáveis, a exemplo do que acontece no consumo socialmente responsável, costuma reverberar sobre as escolhas alimentícias dos sujeitos.

Em muitos casos, os hábitos alimentares atuam como um fator de identidade e memória. Acerca disso, Rubem (2013) afirma que os ritos alimentares costumam ter o papel de resguardar a herança gastronômica das culturas. Essa pode ser a razão pela qual comportamentos de consumo que priorizam o aspecto socioambiental expliquem as escolhas alimentícias. Não há como desconsiderar, nesse âmbito, que os consumidores têm ponderado sobre os impactos sociais e ambientais nas suas decisões de consumo, criando modelos mentais para a aquisição de produtos que dialogam com os seus ideais éticos (PÉREZ-BAREA, et al., 2017).

Por último, apresenta-se a confirmação da $\mathrm{H} 5(+)$. Diante desse achado, foi elucidado que a influência social também explica a formulação dos hábitos alimentares dos indivíduos. Esse resultado dialoga com os estudos de Batista e Lima (2013) e, mais recentemente, com Vaz e Bennemann (2018). Isso porque, segundo os autores, a alimentação não é apenas uma necessidade física, mas sobretudo um ato coletivo sobre o qual há diferentes interações sociais.

Tais interações, de acordo com Toral e Slater (2007), têm impacto direto e substancial sobre o consumo de alimentos. Algumas ações, a exemplo do preparo dos alimentos, utensílios utilizados e ingestão (VAZ; BENNEMANN, 2018), costumam ser formuladas e direcionadas por influências sociais. Não por acaso, a avaliação e opinião de outros indivíduos é tão relevante sobre os hábitos alimentares dos sujeitos.

\section{CONCLUSÃO}

Conforme esperado, este estudo averiguou a força de alguns atributos comportamentais (consumo socialmente responsável, influência social e hábitos alimentares dos turistas) sobre a intenção de visitar destinos ecogastronômicos. Adicionalmente, avaliou dois possíveis precedentes dos hábitos alimentares dos turistas.

Diferentemente do que se esperava pelos pressupostos teóricos, o consumo socialmente responsável, a influência social e os hábitos alimentares dos turistas parecem não motivar o interesse pela visitação. Isso contradiz as características ambiental, social e gastronômica que podem ser fomentadas por essas destinações e leva a crer que pode haver uma incongruência entre o posicionamento desses destinos e a sua demanda potencial.

$\mathrm{Na}$ verdade, o interesse pela visita nessas localidades não é estimulado pelos comportamentos socio e ambientalmente responsáveis, muito embora os pressupostos teóricos indiquem que a ecogastronomia se proponha a ser um modelo alternativo e sustentável de alimentação. É possível que, no caso de destinos com tal posicionamento, a motivação esteja mais fortemente atrelada ao hedonismo e ao apelo experiencial da atividade turística do que propriamente ao argumento de sustentabilidade gastronômica. 
De acordo com os achados desta pesquisa, também se conclui que a opinião dos grupos sociais com as quais se tem aproximação, tais como familiares e amigos, não é explicativa sobre a intenção de visita. Acredita-se, nesse ponto, que a demanda constituinte dos destinos ecogastronômicos seja formulada por indivíduos cujos valores particulares são mais assertivos em seus comportamentos de consumo turístico do que as normas e padrões sociais dos grupos.

Outro achado inesperado foi a indiferença dos hábitos alimentares dos sujeitos sobre a intenção de visitar os destinos ecogastronômicos. É prudente acreditar, nesse caso, que a qualidade gastronômica não é determinante no interesse de visita. Isso pode estar associado a razões psicológicas, a exemplo da neofilia (aversão ao novo), fato que poderia implicar na repulsa ou desagrado com alimentos diferentes do habitual, a exemplo daqueles que são encontrados ao longo de uma viagem.

Como uma análise complementar, encontrou-se que a formulação dos hábitos alimentares dos indivíduos é paralelamente explicada pelo consumo socialmente responsável e pela influência social. Isso está alinhado com o que se esperava, uma vez que a alimentação é, para além de uma necessidade fisiológica, um ato social e carregado de influências culturais enraizadas no macroambiente dos consumidores. De todo modo, essa escolha alimentar não parece implicar sobre a intenção de visita.

Os resultados elementares deste trabalho apontam para algumas contribuições acadêmicas e gerenciais. Para a academia, destaca que, muito embora existam relações teóricas entre os construtos averiguados, não há consistência entre eles diante do contexto de destinos ecogastronômicos. Fomenta, assim, a discussão de que alguns modelos alternativos e sustentáveis da atividade turística são, na verdade, mais uma oportunidade hedônica.
Aos estrategistas e profissionais do marketing, este estudo apresenta enquanto uma das principais contribuições a necessidade de apontar o argumento da ecogastronomia nos destinos para a qualidade hedônica e experiencial dela resultante. Isso porque, no caso da atividade turística, as características social, ambiental e gastronômica não parecem ser os componentes determinantes da demanda.

Destaca-se que as limitações deste estudo estão na concentração regional da amostra e na impossibilidade de uma amostragem probabilística. Logo, os resultados podem sofrer variações a depender do contexto e de fatores psicológicos. Para estudos futuros, sugerese averiguar de forma mais aprofundada como o prazer e a experiência, elementos marcantes do turismo, podem sobrepor argumentos centrais da ecogastronomia quando ela está associada aos destinos turísticos.

\section{REFERÊNCIAS}

ALDERIGHI, Marco; BIANCHI, Carluccio; LORENZINI, Eleonora. O impacto das especialidades alimentares locais na decisão de (re)visitar um destino turístico: expansão do mercado ou roubo de negócios? Gestão de Turismo, v. 57, p. 323-333, 2016.

BATISTA, Maria Toscano; LIMA, Maria Luísa. Quem está comendo comigo?

Influência social indireta no comportamento alimentar ambivalente.

Psicologia: Reflexão e Crítica, p. 113121, 2013.

BERBEL-PINEDA, J. M.; PALACIOSFLORENCIO, B.; RAMÍREZHURTADO, J. M.; SANTOS-ROLDÁN, L. Gastronomic experience as a factor of motivation in the tourist movements.

International Journal of Gastronomy and Food Science, v. 18, 2019. 
BEVILACQUA, S., SILVA, F.R.; SILVA, C.S. Além dos Alimentos Funcionais e Fitness: Desinformação e dieta sob viés emocional. Consumer Behavior Review, v. 2, n. 2, p. 84-95, 2018.

BLANCO, Luis et al. Una aproximación al turismo Slow: el turismo Slow en las Cittaslow de España. Investigaciones Turísticas, n. 1, p. 122-133, 2011.

BALEM, Tatiana Aparecida et al. As transformações alimentares na sociedade moderna: a colonização do alimento natural pelo alimento industrial. Revista Espacios, v. 38, n. 47, 2017.

CARDOSO, Susana et al. Escolhas e hábitos alimentares em adolescentes: associação com padrões alimentares do agregado familiar. Revista Portuguesa de Saúde Pública, v. 33, n. 2, p. 128-136, 2015.

CASTRO NETO, Nelson et al. Produção orgânica: uma potencialidade estratégica para a agricultura familiar. Revista Percurso, v. 2, n. 2, p. 73-95, 2010.

CESAR, Pedro Henrique et al. Gestão Sustentável: avaliação da responsabilidade socioambiental em meios de hospedagem no litoral norte da Paraíba. Revista Brasileira de Ecoturismo (RBEcotur), v. 11, n. 3, p. 422-448, 2018.

COHEN, Erik; AVIELI, Nir. Alimentos no turismo: atração e impedimento. Anais do turismo Pesquisa, v. 31, n. 4, p. 755-778, 2004.

COSTA, M. F.; COSTA, C. E.; ANGELO, C. F.; MORAES, W. F. A. Perceived competitive advantage of soccer clubs: a study based on the resource-based view.

RAUSP Management Journal, v. 53, p. 23-34, 2018.

ELLIS, Ashleigh et al. O que é turismo de comida? Gestão do Turismo, v. 68, p. 250-263, 2018.
FONSECA, Alexandre Brasil; SOUZA, Thaís Salema Nogueira de; FROZI, Daniela Sanches; PEREIRA, Rosangela Alves. Modernidade alimentar e consumo de alimentos: contribuições socioantropológicas para a pesquisa em nutrição. Ciênc. saúde coletiva [on-line], v. 16, n. 9, pp.3853-3862, 2011.

FREEDMAN, Irith. Cultural specificity in food choice - The case of ethnography in Japan. Appetite, v. 96, p. 138-146, 2016.

GÂNDARA, José Manoel Gonçalves; GIMENES, M. H. S. G.;

MASCARENHAS, R. G. Reflexões sobre o Turismo Gastronômico na perspectiva da sociedade dos sonhos. Segmentação do mercado turístico-estudos, produtos e perspectivas. Barueri: Manole, p. 179191, 2009.

GARCIA, Rosa Wanda Diez.

Representações sociais da alimentação e saúde e suas repercussões no comportamento alimentar. Physis: revista de saúde coletiva, v. 7, p. 51-68, 1997.

GIL, Antônio Carlos. Métodos e técnicas de pesquisa social. 6. ed. São Paulo. Editora Atlas SA, 2008.

GIMENES-MINASSE, Maria Henriqueta. Para turista ver e provar: dos usos do patrimônio gastronômico no contexto do turismo. Tessituras: Revista de Antropologia e Arqueologia, v. 3, n. 2, p. $175,2015$.

Grzelak-Kostulska, Elżbieta, Beata Hołowiecka, and Grzegorz Kwiatkowski. "Cittaslow International Network: An Example of a Globalization Idea?" In The Scale of Globalization. Think Globally, Act Locally, Change Individually in the 21st Century, 186-192. Ostrava: University of Ostrava, 2011. ISBN 978-80-7368-9636

http://conference.osu.eu/globalization/publ 2011/186-192 Grzelak-KostulskaHolowiecka-Kwiatkowski.pdf. 
HASFORD, Jonathan; FARMER, Adam.

Responsible you, despicable me:

Contrasting competitor inferences from socially responsible behavior. Journal of Business Research, v. 69, n. 3, p. 12341241, 2016.

HAIR Jr., J.F.; BLACK, W.C.; BABIN, B.J.; ANDERSON, R.E.; TATHAM, R.L. Análise multivariada de dados. 6.ed. Porto Alegre, Bookman, 2009. 688p.

HILLEL, David; BELHASSEN, Yaniv; SHANI, Amir. What makes a gastronomic destination attractive? Evidence from the Israeli Negev. Tourism Management, v. 36, p. 200-209, 2013.

IRLENBUSCH, B.; SAXLER, D. J. The role of social information, market framing, and diffusion of responsibility as determinants of socially responsible behavior. Journal of Behavioral and Experimental Economics, v. 80, p. 141$161,2019$.

KELMAN, Herbert C. Interesses, relacionamentos, identidades: Três questões centrais para indivíduos e grupos na negociação de seu ambiente social.

Annu Rev. Psychol. V. 57, p. 1-26, 2006.

KIVELA, Jakša; CROTTS, John C. Tourism and gastronomy: Gastronomy's influence on how tourists experience a destination. Journal of Hospitality \& Tourism Research, v. 30, n. 3, p. 354377, 2006.

LAU, Teck-Chai. Towards socially responsible consumption: an evaluation of religiosity and money ethics.

International Journal of Trade, Economics and Finance, v. 1, n. 1, p. 32, 2010 .

LEE, Kuan-Huei; SCOTT, Noel; PACKER, Jan. Travel lifestyle preferences and destination activity choices of Slow Food members and non-members. Annals of Tourism Research, v. 48, p. 207-220, 2014.

LONG, Lucy M. Política cultural no turismo gastronômico com alimentos étnicos. Revista de Administração de Empresas, v. 58, n. 3, p. 316-324, 2018.

LÓPEZ-GUZMÁN, Tomás;

CAÑIZARES, Sandra María Sánchez. La gastronomía como motivación para viajar. Un estudio sobre el turismo culinario en Córdoba. PASOS. Revista de turismo y patrimonio cultural, v. 10 , n. 5 , p. 575 584, 2012.

\section{MALHOTRA, N. K. Pesquisa de} marketing: uma orientação aplicada. 6.e d. São Paulo. Bookman Editora. 2012.

MAK, ATHENA H, LUMBERS, M., EVES, A., \& CHANG, RC. Fatores que influenciam o consumo de alimentos turísticos. International Journal of Hospitality Management, v. 31, n. 3, p. 928-936, 2012.

MARTINS, Uiara Maria Oliveira; GURGEL, Lorena Ibiapina; MARTINS, José Clerton de Oliveira. Experiências com a gastronomia local: um estudo de caso sobre movimento Slow Food e o turismo gastronômico na cidade de Recife-Brasil.

Passos Revista de Turismo e patrimônio cultural. v. 14, nr.1, p229-241, 2016.

NASCIMENTO, T. M. Examinando o domínio do comportamento pró-ambiental na promoção do bem-estar individual e coletivo. Consumer Behavior Review, v. 3 , n. 1, p. 27-41, 2019.

NASCIMENTO, E. R.; COSTA, M. F.; OLIVEIRA, K. K. Comunicação persuasiva na internet por meio do youtube: é possível aumentar a preocupação ambiental e o envolvimento do consumidor com a sustentabilidade?

Teoria e Prática em Administração, v. 5, p. 1-24, 2015. 
REJOWSKI, Mirian; RUBIM, Rebeca Elster. Ecogastronomia-A busca pela ética e o prazer na alimentação e sua influência na relação homem x natureza. IX

Seminário da Associação Nacional Pesquisa e Pós-Graduação em Turismo, Universidade Anhembi Morumbi-São Paulo, 2012.

MIELE, Mara; MURDOCH, Jonathan. A estética prática das cozinhas tradicionais: comida lenta na Toscana. Sociologia Ruralis, v. 42, n. 4, p. 312- 328, 2002.

GIL, Antônio Carlos. Métodos e técnicas de pesquisa social. 6 . ed. São Paulo. Editora Atlas SA, 2008.

PECCINI, Rosana. A Gastronomia e o Turismo. Rosa dos Ventos-Turismo e Hospitalidade, v. 5, n. 2, p. 206-2017, 2013.

PEREIRA, G. R.; VEIGA, A. R.; OLIVEIRA JÚNIOR, J. C.; OLIVEIRA, H. C. Marketing verde: Fatores da geração $\mathrm{Z}$ sobre questões ambientes. Consumer Behavior Review, v. 1, n. 2, p. 58-72, 2017.

PÉREZ-BAREA, J.J.; FERNÁNDEZNAVARRO, F.; MONTERO-SIMÓ, M.J.; ARAQUE-PADILLA, R. Um índice de consumo socialmente responsável baseado na redução de dimensionalidade não linear e na análise de sensibilidade global.

Applied Soft Computing, v. 69, p. 599609, 2018.

PINHEIRO, Karina Aragão de Paula Nobre. História dos hábitos alimentares ocidentais. Universitas: Ciências da Saúde, v.3, n. 1, p. 173-190, 2008.

PIETRYKOWSKI, Bruce. You are what you eat: The social economy of the slow food movement. Review of social economy, v. 62, n. 3, p. 307-321, 2004.

RODRIGUES, Paulo Roberto Grangeiro. Influência social, minorias ativas e desenvolvimento moral. Psicologia \&

Sociedade, v. 30, n. 1, 2018.

RUBIM, Rebeca Elster. A Ecogastronomia nos Cursos Superiores de Gastronomia do Estado de São Paulo: Conceitos, Aplicações e Cenário Observado. ROSA DOS VENTOS-Turismo e Hospitalidade, v. 5, n. 2, p. 280-292, 2013.

SACCOL, Amarolinda Zanela. Um retorno ao básico: compreendendo os paradigmas de pesquisa e sua aplicação na pesquisa em administração. Revista de Administração da UFSM, v. 2, n. 2, p. 250-269, 2009.

SCHNEIDER, Kamila Guimarães. A ecologia no prato: uma análise etnográfica sobre os conceitos de ecogastronomia e prazer. Alamedas, v. 6, n. 2, p. 195-2016, 2018.

SENGEL, Tarik.; KARAGOZ, Aysen.; CETIN, Gurel; DINCER, Fusun IstambulluI; ERTUGRAL, MUGAN, Suna; BALIK, Mehtap. Abordagem dos turistas à comida local. Procedia Ciências Sociais e Comportamentais, v. 195, p. 429-437, 2015.

SILKES, Carol A.; CAI, Liping A.; LEHTO, Xinran Y. Marketing Para O Turista Culinário. Journal of Travel \& Tourism Marketing, v.30, n. 4, p. 335349, 2013.

SINDELAR, Fernanda C.W. et al. O perfil de consumo e percepção em relação aos alimentos orgânicos dos consumidores gaúchos. Revista Brasileira de Agroecologia, v. 13, n. 5, p. 211, 2018.

TOMAZONI, Ana Maria Ruiz.

Transformando hábitos alimentares em prazer e saúde: educando com alimentos. Interespe. Interdisciplinaridade e Espiritualidade na Educação. ISSN 2179-7498, v. 1, n. 9, p. 10-17, 2017. 
TORAL, Natacha; SLATER, Betzabeth. Abordagem do modelo transteórico no comportamento alimentar. Ciência \& Saúde Coletiva, v. 12, p. 1641-1650, 2007.

VAZ, Diana Souza Santos; BENNEMANN, Rose Mari.

Comportamento alimentar e hábito alimentar: uma revisão. Revista UNINGÁ

Review, v. 20, n. 1, p. 108-112, 2018.

YEONG, Gug Kim; ANITA, Eves.

Construção e validação de uma escala para medir a motivação turística para consumir alimentos locais. Tourism Management, v. 33 , n. 6 , p. $1458-1467,2012$.

WEBB, D.J.; MOHR, L.A.; HARRIS, K.E. A re-examination of socially responsible consumption and its measurement.

Journal of Business Research, v. 61, n. 2, p. 91-98, 2008.

ZOLLO, Anna. Dal Turismo, Rurale A. Quello. Eco-Gastronomico: Il Caso Del Sannio Beneventano. Revista Focus, v VI, n. 13, p. 145-151, 2015.

\footnotetext{
'Mestra em Gestão de Empresas Hoteleiras e Turísticas pelo Programa de Pós-Graduação em Hotelaria e Turismo (PPHTUR) da Universidade Federal de Pernambuco (UFPE). Graduada em Administração de Empresas - FAA Faculdade Alagoana de Administração (2013). MBA em Administração - Getão de Negócios - UNIT Universidade Tiradentes (2016).

ii Mestra em Hotelaria e Turismo pelo PPHTUR/UFPE, vinculada à linha Gestão de Empresas Hoteleiras e Turísticas.

iii Doutor em Administração pela FEA/USP. Doutor em Administração pelo PROPAD/UFPE. ViceCoordenador do Programa de Pós-Graduação em Gestão, Inovação e Consumo - PPGIC (Mestrado Acadêmico) da Universidade Federal de Pernambuco, Campus Caruaru.
} 